\title{
Development of a innovative solution for energy recovery from the flow exhaust gas on bench test facility of turbofan aircraft engine through the use of innovative design methods:
}

\author{
Definition of the process and the operating environment \\ Amine RAHOUI ${ }^{1}$, Zinab AALAOUI ${ }^{1}$ \\ ${ }^{1}$ Applied Mechanics and Technologies Research Laboratory/ ENSET University Mohammed 5 Rabat, Morocco
}

\begin{abstract}
Civil aviation is driven nowadays by exceptional growth in the number of passengers. It should double or even triple by 2050 and thus, all industrials also plan to double the number of device delivery by mid-century. Responsible for about $2 \%$ of carbon dioxide on the planet, they must now deal with the environmental issues facing the sector.

At this moment in the world, several lines of research focus on increasing the efficiency of aircraft engines, development of new engines, efficient technologies, sustainable sources of alternative fuels and improved management air traffic on the ground and in flight [1].

The present work deals with a research focused on the engine test when passing in review in repair facilities. This operation which consist in making engine running while the cycles to test its performance in a test bench are studied to define a technological solution to reduce $\mathrm{CO2}$ carbon footprint of the aircraft engine in this phase of the cycle of life. The idea is to produce electrical energy during these tests. To achieve this, we will highlight the case of a type bench facility for a specific airplane engines. As a result high-performance analysis tools are implemented to define the most suitable technological solution that ensures maximum efficiency, meets the functional and regulatory requirements taking into account the force of integration with the existing and cost optimization.

In this paper we present the summary of the working definition of the research process for the final term set in the operating environment integration relevance that provides bench test and level of innovation that provides the methods selected.
\end{abstract}

Keywords- Turbofan Engine, Design, Simulation, Flow, Engine Test, Energy, FEM, Bench test facility

\section{INTRODUCTION}

Air traffic grew strongly, to support the growth of orders; the performance, the economic and the environmental issues are first rate for all aircraft manufacturers. They are increasingly involved in the battle against climate change through direct action off the main causal link consumption of fossil fuels, it is the vision that the manufacturers, carriers and airports show up. Without forgetting of course the economic challenge posed by the reduction of operating costs [2]. The goal for all is to increase the efficiency of the aviation industry and reduce carbon emissions footprint of the entire life cycle of the major elements of an airplane. Today, manufacturers are betting on technological advances: energy performance of engines, improved aerodynamics, lightweight of structures, optimized trajectories [3].

The desired result of this work is to contribute to the definition of the testing environment of the inner engine of bench facilities and start the first steps in developing a technological solution for energy recovery the flow of exhaust gas from the test bench generated by jet engines during operation (Fig. 01).

The approach outlined in this study and the results sought. For a better understanding, in the first place you will have a summary of the literature review on aircraft engines and later that of the bench testing of engines, during which we will see in greater detail a particular case of a turbofan engine [4]. Furthermore this paper doesn't include the summary and the process of the design method on our current research, this last it about an innovative design methods, mainly axiomatic design combined to design for assembly both defined as an analytical tool $[5,6]$. At the end, we will detail the steps and results of the study of the operation of test stand regarding the thermodynamic state of the exhaust gases from the jet engine off the bench. These results will be used as input data for modeling the technological solution. Also, a summary of conditions of the operating environment will be established, which will used later in our final research [7].

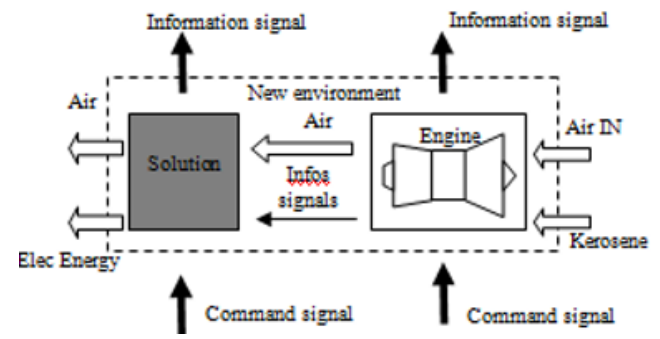

Fig. 1, Simplified layout of the principle of technological solution

\section{STUDY CASE}

For our research subject, we are required to follow a study approach; this must include the complexity of the topic and the major elements that fit into its constitution. Afterward, we will conduct a study on the bench with the internal motor to set the operating environment of the technological solution that will input data in our design study. In a first, the configuration considered is a test bench with flow paths unhindered.

The aim is to define the energy potential of the bench in order to open the axis towards a improvement or breaking innovation for possible technological solution.

\section{II.1. GEOMETRIC MODÉLISATION}

\section{- Bench test facility}

The building is $70 \mathrm{~m}$ length, $11 \mathrm{~m}$ width, height of $13 \mathrm{~m}$ form the inlet air and $17 \mathrm{~m}$ height for the from the exhaust air, 
in addition to other dimensions used for geometric modeling. The engine is positioned inside the test bench (Fig. 02)

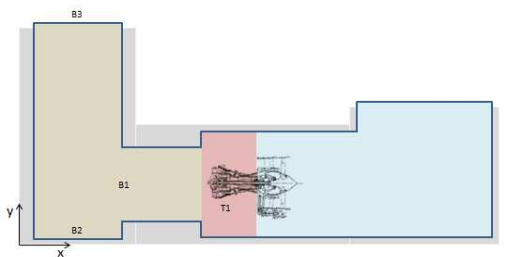

Fig. 02, The landmarks of the bench test.

In à departure we will take the characteristics of the most used engine in the world the CFM, especially the CFM56. The data of this engine will be the boundary conditions on which we will build for the test operation phase; this is as following [4]:

- Mass flow of incoming air: At full power, the CFM56 jet engine aspire air of a mass flow $466 \mathrm{~kg} / \mathrm{s}$.

- Speed of the output of the exhaust gas by the nozzle: The exhaust gases are ejected from the nozzle of the CFM56-5B with a speed of Mach 0.82, $1007 \mathrm{Km} / \mathrm{h}$.

- Temperature of exhaust gas: The temperature of the exhaust gas, or EGT (Exhaust Gas Temperature), is $550^{\circ} \mathrm{C}$.

Based on the dimensions information, we design on CATIA V5 Module CATPART 3D geometric model test bench for the flow simulation [8].

- CFM56-5B engine nacelle

To simulate the operation of the test bench, we must model the section of the fan and the exhaust and incorporate it into the model of the test bench. In this step, we will focus only the flow of air at the inlet and the outlet of the turbofan engine, so that the very complex and many internal components of the engine will not be taken into account. To model the engine, used engine plans dimensions of CFM56 $[9,10]$.

\section{II.2. NUMERIC MODELING OF FINITE ELEMENT ANALYSIS}

\section{II.2.1. NUMERIC PROCESSING TOOLS :}

One general, pretreatment of the model is made in the CFX fluid mechanics workshop of ANSYS software [11]. For the geometric processing of the 3D model, we import the geometry developed in STP format Modeler Design module. The advantage of the ANSYS meshing module is detect automatically the areas requiring mesh refinement such geometries having curvatures and those having narrow dimensions.

\section{II.2.2. THE FLUID DOMAIN OF NUMERIC MODEL}

To simulate the flow of air during operation of the test bench, according to the solid geometry in the model, we prepare the model defining the empty volume of the interior of the test bench, as well as area volumes at the inlet and at the outlet of the fluid bench test which is our study domain to be able to identify the air flow in these positions predefined previously.

\section{II.2.3. THE MESH GENERATION OF NUMERIC MODEL}

Once the geometry is prepared, we proceeds to generate the mesh by the Mesher Module and we introduce the mesh settings for the model.

The mesh refinement is imperative in the surrounding area of geometries with reduced bend radius or an acute angle. This is necessary for the convergence of the calculation. A non-refined mesh properly, and a high number of elements, will risk to involve a time calculation result, and without possible convergence of results.

\section{II.2.4. THE BOUNDARY CONDITIONS OF NUMERIC MODEL}

After mesh generation, we configure the initial conditions and boundary conditions of the model. The generated mesh is imported into CFX-PreEngine module [12].

- The boundary conditions 1 : Interior walls of the test bench

- The boundary conditions 2: The exterior of the test bench

- The boundary conditions 3: Wind Effect

- The boundary conditions 4: Engine body

- The boundary conditions 5: air intake of the engine

- The boundary conditions 6: Exhaust nozzle of engine

\section{II.2.5. NUMERICAL SIMULATION FEM}

The numerical simulation is done by the CFD solver ANSYS. For the convergence precisely of the solution in the case of our model with a large number of elements, it is advisable to select the "Double Precision" method, giving a smaller error than the "Single Precision", but this last which nevertheless increase the computation time [12].

\section{RESULTS AND POST TREATMENT}

In a first place, we are going to present the results of calculation for the case of the bench test without obstacle of the cylindrical grate in extension of the tunnel of the bench test exhaust; then the complementary study for the case with the grate noise reducing, this is to identify the potential of energy recovery in both configurations.

\section{POST-TREATMENT OF THE RESULTS : CASE WITHOUT OBSTACLE}

The flow arrives inside the cylindrical tunnel to go out according to an axial direction to the wall of the tunnel.

The results of the calculation are transmitted to the module CFD-PostEngine of ANSYS the interface of which shows and posts the results of variables involved in the calculation, in particular the mass and the speed, the thermal transfer as well as the turbulences. The displays of the results are realized by some present tools in the module PostEngine, in particular the function "Streamline" and "Volume Rendering". The function "Streamline" models the lines of current in the fluid domain, and the function "Volume Rendering" models the distribution of the parameters in the fluid domain, in particular the pressure and the temperature. The figure 03 illustrates the aspect of the lines of current inside the entire bench test.

At first view, we notice that the airflow inside the bench test presents much turbulence, which is for the admission or for the exhaust. The figure 04 represents the airflow to the area of the turbojet engine.
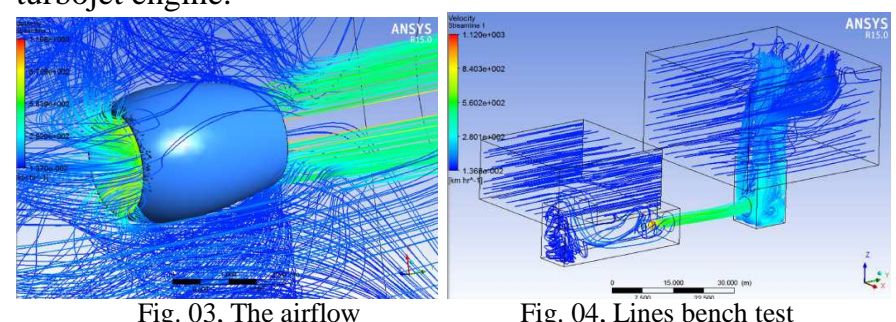

For our two scenarios, we are going to visualize the state thermodynamics of the model in two locations of the bench of test. The first one that of the opening of the bench of test on the open air the second is at the end of the tunnel inside the bench test. To make it, we model the section of exhaust of the bench test by a plan posting the distribution of the airflow and its temperature. The figure 05 and 06 illustrates respectively the speed and the temperature of air going out at the level of the limit section of the exhaust of the bench test. 

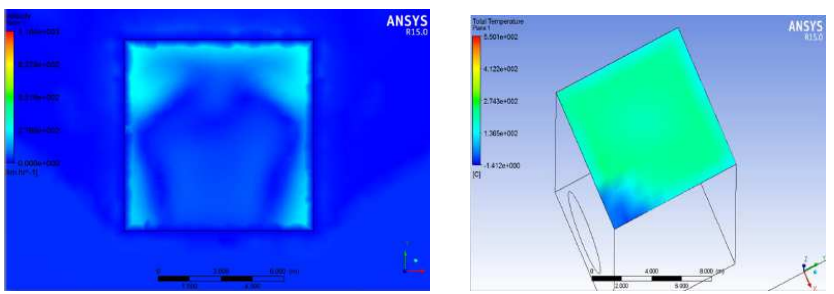

Fig. 05, The speed of outgoing air Fig. 06, The temperature of outgoing air

According to the figure 05, we notice that the exhaust flow of the bench test presents a particular distribution, what makes our installation of turbines will based on this distribution to find the solution adequate to the opening of the bench test.

Furthermore than the distribution of the temperature, we can define also the average of the temperature in the section of the bench test exhaust opening. This average is calculated by the tool "function calculator" in the module CFD-PostEngine. The average temperature at this section is $466,989 \mathrm{~K}\left(193,839{ }^{\circ} \mathrm{C}\right)$. The maximal temperature in this section is $517,523 \mathrm{~K}$ $\left(244,373^{\circ} \mathrm{C}\right)$. If we summarize the thermodynamics state of exhaust gases at this section of the bench test we found the result of the table below;

\begin{tabular}{|l|c|}
\hline Average speed & $70 \mathrm{~m} / \mathrm{s}$ \\
\hline Maximum speed & $111 \mathrm{~m} / \mathrm{s}$ \\
\hline Average temperature & $194{ }^{\circ} \mathrm{C}$ \\
\hline Maximum temperature & $244^{\circ} \mathrm{C}$ \\
\hline
\end{tabular}

We can continue to exploit the results to know the flow going out of the tunnel because is essential to know the state of power to be got back of the bench of test. To know the flow going out of the tunnel, we return to the simulation of the functioning of the bench test and through the module CFD-PostEngine we take the state thermodynamics in the section of escape opening of the tunnel before the anti-noise grate.

The Figure 07 and 08 represent the distribution of the speed of the flow as well as the temperature at this level of this section.

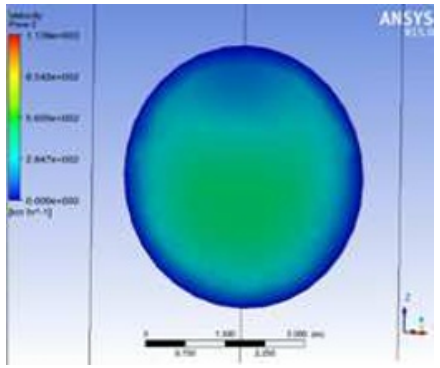

Fig. 07, Flow speed

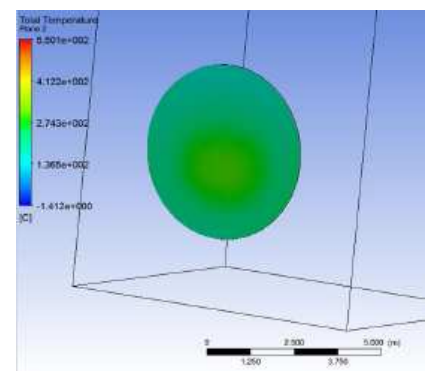

Fig. 08, Temperature
We notice that the distribution of the speed and the temperature of the flow of the anti-noise grate is quasi-homogeneous on all the section of end of the tunnel, the average results speed 77 $\mathrm{m} / \mathrm{s}$ Average temperature $225^{\circ} \mathrm{C}$

This simulation allowed visualizing the flow of exhaust gases inside the bench test during its functioning. This step is essential to know the thermodynamic state of the flow of exhaust gases at the exit of the bench test, where we shall study to place possibly our installation of energy recovery.

We notice that the airflow going out of the escape of the bench test takes a uniform and central distribution concerning the speed of gases and temperature; all the results will be taken into account in our next stage of conception of solutions of energy recovery.

\section{CONCLUSION ET PERSPECTIVES}

In this communication, we saw globally the major elements which intervene on the process and the operating environment in the chain of realization of the test of turbofan engines, while describing this latter.

I recall that the purpose is the development of a technological solution for energy recovery in the flow of exhaust gases from bench test of jet engines using the methods of innovative design; this obviously will go through a definition the approach and the operating environment that we have initiated and summarized in a previous paper.

This numerical simulation used to visualize the flow of the exhaust gas inside the test bed during operation. This step is essential in order to know the thermodynamic state of flow of exhaust gas at the outlet of the test bench, where they eventually put our energy recovery plant. A detailed analysis of the results obtained has allowed us the input information for the development of the technology solution.

In this stage we assured the definition of scenarios in developing position and the functional operating parameters. After, we have listed the steps for study development to achieve this research, by which it cites;

- Choice between breaking or improvement.

- Innovative design of a new wing concept.

- Experimentation in operating prototype of a new concept of turbine.

We identified other research areas that intersect with our like;

- Study inverse to define the impact of the technological solution on the bench structure.

- Reverse Study of the impact of the technological solution on the engine to determine the influence of the correlation parameters.

- Flexibility of the technological solution in digital model to ensure full integration with any kind of bench and test environment.

For this purpose, the design approach is to study the application of the axiomatic design method and design method for assembling each separately. This is according to relevancy of each level of development.

Second step is to apply the optimal model of these two methods based on maximizing the performance of the molded part while respecting the parameters of each method.

At this point, we may open and make a prioritization between two axes, a total integration solution or breakthrough solution that will lead to changes if the existing.

\section{REFERENCES}

[1] PUY. GOYNE, Y. PLAYS, P. LEPOURRY, J. BESSE «Initiation à l'aéronautique » Editions CEPADUES

[2] Shannon Ackert, Engine Maintenance Concepts for Financiers Elements of Turbofan Shop Maintenance Costs, 2011

[3] E. Diez Lledo, Diagnostic et Pronostic de défaillances dans des composants d'un moteur d'avion, 2008

[4] Thaddeus W. Fowler, Jet Engine and Propulsion Sysytems for Engineers, 1989

[5] O. Kulaka, S.Cebib, C. Kahraman, Applications of axiomatic design principles: A literature review, 2010.

[6] R. A. Shirwaikera, G. E. Okudanb, Contributions of TRIZ and axiomatic design to leanness in design: an investigation, 2011.

[7] F. Arnoux, Modéliser et organiser la conception innovante : cas de l'innovation radicale dans les systèmes d'énergie aéronautiques, 2013.

[8] Dassault Systèmes, Catia manual V5 R20, 2011

[9] A. Collignan, Méthode d'optimisation et d'aide à la décision en conception mécanique : Application à une structure aéronautique, 2012

[10] R. Maculet, M. Daniel, Conception, modélisation géométrique et contraintes en CAO : Une synthèse, 2003

[11] Ansys, Ansys manual ICEM CFD R13.0, 2007

[12] M. Michaud, méthodologie de modélisation unifiée en cao aéronautique : Application aux tôles et gabarits de découpe, 2004 